\title{
Morphological and Molecular Characterization of a Myxosporean Parasite Infecting the Skeletal Musculature of an Ornamental Fish Species from the Amazon River
}

Sónia Rocha ${ }^{1,2}$, Graça Casal ${ }^{1,3}$, Edilson Matos ${ }^{4}$, Patrícia Matos ${ }^{5}$, José Mauro Silva ${ }^{4}$, Ângela Alves ${ }^{2}$ and Carlos Azevedo ${ }^{1,2}$

1. Laboratory of Animal Pathology, Interdisciplinary Centre of Marine and Environmental Research (CIIMAR), University of Porto, Porto, Portugal.

2. Laboratory of Cell Biology, Institute of Biomedical Sciences Abel Salazar (ICBAS), University of Porto, Porto, Portugal.

3. Department of Sciences, High Institute of Health Sciences - North, CESPU, Gandra, Portugal.

4. Carlos Azevedo Research Laboratory, Federal Rural University of Amazonia, Belém, State of Pará, Brazil.

5. Edilson Matos Research Laboratory, Federal University of Pará, Belém, State of Pará, Brazil.

The freshwater teleost fish Symphysodon aequifasciatus Pellegrin, 1904, commonly known as blue discus, is endemic of the Amazonic basin in Brazil, Peru and Colombia. Endowed by a beautiful shape and coloration, this is a popular ornamental species that presents high commercial value worldwide. Its overexploitation has, however, been leading to the decline of wild populations, but other factors may be involved, such as parasitic diseases. Parasites of the class Myxosporea Bütschli, 1881, and more specifically of the genus Kudoa Meglitisch, 1947, are important pathogens of fish, both at the economic and at the ecological level [1]. The study here presented relies on ultrastructural and molecular data to characterize a species of Kudoa that was found infecting the muscle of several specimens of blue discus captured from the Amazon basin in Brazil.

Infected tissue was observed and photographed using the light microscope (LM) for measurement of fresh cysts and myxospores, and then prepared for transmission electron microscopy (TEM) and molecular analysis. The SSU rRNA gene was sequenced using both eukaryotic and kudoid-specific primers. For inferring phylogenetic relationships, neighbour-joining (NJ), maximum parsimony (MP) and maximum likelihood (ML) methodologies were performed in MEGA 5.05.

Prevalence of infection was estimated at $80 \%$. Numerous whitish fusiform pseudocysts were observed among the skeletal myofibers (Fig. 1(1)). Myxospores quadrangular with rounded ends in apical view, measuring $5.3 \pm 0.7 \mu \mathrm{m}$ in length and $7.3 \pm 0.5(6.8-7.8) \mu \mathrm{m}$ in width. Myxospores wall composed by four symmetric valves, smooth and united along a curved suture line, and surrounding four pyriform polar capsules, equal-sized and measuring $3.8 \pm 0.5 \mu \mathrm{m}$ in length and $2.5 \pm 0.5 \mu \mathrm{m}$ in width. The polar capsules were located at the same level, two by two in opposite sides of the myxospores longitudinal axis, and each containing a polar filament coiled in 2 turns (Fig. 1(2) and Fig.1(3)).

The morphological and molecular data obtained identify this parasite as a possible new member of the genus Kudoa that clusters together with Kudoa orbicularis, the only other freshwater SSU rRNA sequence of this genus in GenBank. The phylogenetic analysis further reveals tissue tropism as an important evolutionary signal for Kudoa (Fig. 1(4)) [2]. 


\section{References :}

[1] J. Lom and I. Dyková, Folia Parasitologica 53 (2006) p. 1.

[2] The authors acknowledge "FCT" within the scope of the Ph.D. fellowship grant attributed to S. Rocha (SFRH/BD/92661/2013); the Eng António de Almeida Foundation; the project EUCVOA (NORTE-07-0162-FEDER-000116); CAPES (“Process 88881.064967/2014-01-PVE”); CNPq ("Process 441645/2014-3; Edital Universal 14/2014”); and SISBIO-ICMBIO/IBAMA (Brasília, Brazil).
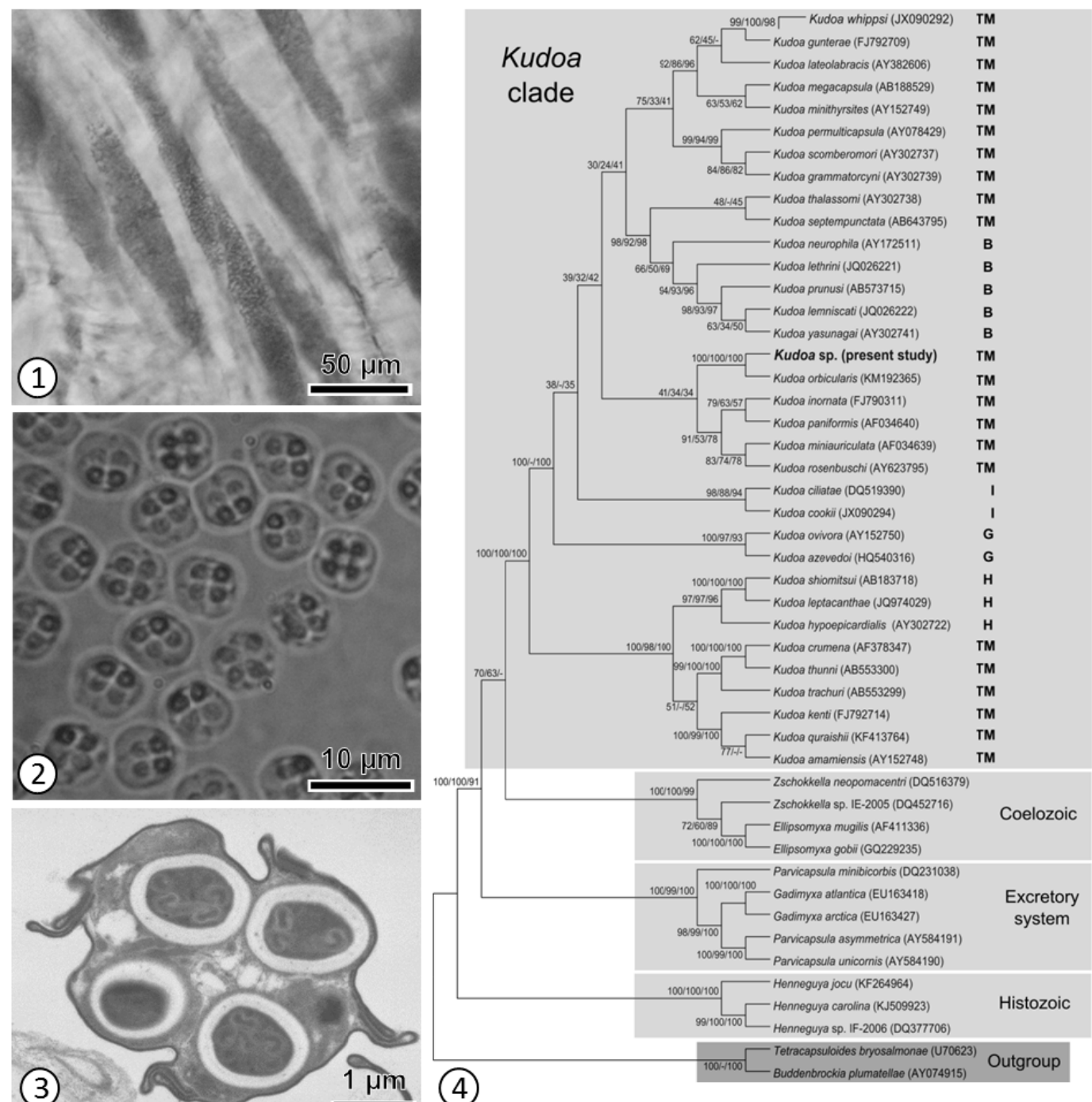

Figure 1. (1) LM micrograph showing numerous pseudocysts in the muscle; (2) LM micrograph showing numerous free fresh mature myxospores, after rupture of a pseudocyst; (3) TEM micrograph revealing the overall ultrastructure of a myxospore in transverse section; (4) NJ, MP and ML tree for the SSU rRNA sequences of Kudoa sp. and other selected marine myxosporeans. GenBank accession numbers in parentheses after the species name; TM, trunk muscle; B, brain; I, intestine; G, gonad; H, heart. 